\title{
Idades U-Pb em Zircão de Alguns Granitos Clássicos da Província Borborema
}

\author{
Benjamim Bley de Brito Neves (bbleybn@ usp.br), Cláudia Regina Passarelli², \\ Miguel Angelo Stipp Basei ${ }^{1}$, Edilton José dos Santos ${ }^{3}$ \\ ${ }^{1}$ Departamento de Mineralogia e Geotectônica - Instituto de Geociências - USP \\ R. do Lago 562, CEP 05508-080, São Paulo, SP, BRA \\ ${ }^{2}$ Centro de Pesquisas G eocronológicas - Instituto de G eociências - USP, São Paulo, SP, BRA \\ ${ }^{3}$ Departamento de Geologia - Centro de Tecnologia e Geociências - UFPE, Recife, PE, BRA
}

Palavras-chave: plutonismo granítico, granitos tipo Conceição, granitos tipo Itaporanga, Província Borborema, Ciclo Brasiliano-Pan Africano.

\section{RESUMO}

A evolução neoproterozóica da Província Borborema, no Nordeste Oriental da plataforma Sul Americana, exibe como característica marcante o plutonismo granítico, objeto de diversas teses e outras publicações em revistas especializadas. Já em 1967, F. F. de Almeida e colaboradores identificaram uma série de tipologias graníticas, Conceição, Itaporanga etc, com base em feições de geologia regional e estudos petrográficos. Estas identificações persistiram praticamente em todas as publicações posteriores, mesmo quando um número significativamente maior de granitos foi observado, com o respaldo de estudos geoquímicos, tectônicos e isotópicos. Neste trabalho, estes tipos clássicos foram analisados pelo método U-Pb em zircão, para sanar uma carência de há muito reclamada pela comunidade, posto que para todos eles preexistiam apenas determinações isotópicas de menor poder de resolução. Estes dados novos foram compatibilizados com outros dados existentes na bibliografia da última década e permitiram definir três etapas principais de magmatismo granítico na Borborema: 650 - 625 Ma; 580 - 570 Ma e 545 - 520 Ma, estes últimos com íntima relação com os eventos de extrusão tectônica da colagem orogênica Brasiliano-Pan Africana, que antecedeu a consolidação de uma massa supercontinental (Gondwana Ocidental).

Keywords: granitic plutonism, Conceição-type granite, Itaporanga-type granite, Borborema Province, Brasiliano-Pan African Cycle.

\section{ABSTRACT}

The Neoproterozoic evolution of the Borborema Province in the east-northeast part of the South American platform exhibits remarkable, much studied granitic plutonism. In 1967 F. F. M. Almeida and co-workers discriminated a series of granitic typologies as "Conceição type", "Itaporanga type" etc, mostly based upon general geological features and petrographic grounds. This preliminary classification has somehow been maintained in all subsequent papers up to now, despite all the newly observed plutons and the newly generated tectonic, geochemical and isotopic data since then. Samples of these classical types of granites from their type-localities were analyzed geochronologically using the U-Pb method in zircons in response to the felt needs of the geological community, because previous age-determinations involved less accurate methods. The new data have been added to all other preexisting U-Pb data (from other granitic bodies) obtained over the last decade, making it possible to recognize three main stages of granitic magmatism for the Borborema Province: 650 - $625 \mathrm{Ma}$, 580 - $570 \mathrm{Ma}$ and 545 - $520 \mathrm{Ma}$. The last group of dates is closely association with the escape tectonics of the BrasilianoPan African collage, which preceded the assembly of the supercontinental landmass of Western Gondwana. 


\section{INTRO DUÇÃO}

A Província Borborema, localizada no Nordeste Oriental do Brasil, teve sua evolução do Neoproterozóico para o Cambriano (Almeida et al., 1981; Brito Neves et al., 2000), consoante sistemas orogênicos ramificados, separados por altos do embasamento (sobretudo das tramas do Paleoproterozóico), que constituíram o suporte fundamental da colagem Brasiliano-Pan Africana. Trata-se de uma província estrutural da plataforma Sul Americana caracterizada, de há muito, pela riqueza e diversidade do magmatismo granítico, o qual perfaz, em termos gerais, cerca de $30 \%$ de todo o conjunto territorial em apreço (Figura 1).

Estas manifestações graníticas se encontram permeando as faixas de supracrustais (Eo-Neoproterozóicas/Cariris Velhos e Neoproterozóicas/Brasilianas), os fragmentos do embasamento paleoproterozóico retrabalhados (intra e interfaixas de supracrustais), as zonas de cisalhamento - muito importantes -, e que deram a forma final geométrico-estrutural da província. Elas são também encontradas nas bordas retrabalhadas dos núcleos cratônicos sinbrasilianos, do São Francisco (Maciço Marginal de Sobradinho, ao sul da província) e de São Luís (Maciço de Granja, ao nortenoroeste da província). Estas rochas graníticas possuem notável acervo bibliográfico, contando-se várias dissertações de mestrado e teses, bem como têm sido pauta de inúmeras reuniões científicas nacionais e internacionais (e. g. ISGAM I e II; Hutton Symposium).

Após alguns trabalhos muito preliminares (como por ex.: Luciano Jacques de Moraes e Djalma Guimarães), há uma referência obrigatória e estopim de todos processos de subseqüentes interesse e investigação científica, e que foi preparado especialmente para um simpósio sobre rochas graníticas da América do Sul, sob patrocínio da UNESCOIUGS, DNPM e da SUDENE. Trata-se do trabalho de Almeida et al. (1967), que se tornou desde então o clássico do tema.
Figura 1. Mapa esquemático dos principais granitos da Província Borborema, baseado em Brito Neves et al. (2000), modificado.

1 - Meruoca; 2 - Mocambo; 3 - Serra da Barriga; 4 - Quixeramobim; 5 - Pereiro; 6 - Umarizal; 7 - Acari e leucogranitos do Seridó; 8 - Barcelona; 9 - Monte das Gameleiras; 10 - Serra da Lagoinha; 11 - Itaporanga; 12 - Conceição; 13 - Serrita; 14 - Salgueiro e Terra Nova; 15 - Triunfo; 16 - Solidão e Tabira; 17 - Teixeira; 18 - Catingueira; 19 - Esperança; 20 - Campina Grande; 21 - Prata; 22 - Serra Branca; 23 - Fazenda Nova; 24 - Moderna; 25 - Rajada; 26 - Serra da Esperança; 27 - Ouro Branco; 28 - Tará; 29 - Xingó; 30 - Coronel João Sá. MCo - Médio Coreaú; CC - Central Ceará; JW-P - JaguaribePotiguar Ocidental; RP - Rio Piranhas; SED - Seridó; JC - São José do Campestre; PAB - Piancó-Alto Brígida (SG - Santana dos Garrotes; RG - Riacho Gravatá); AP - Alto Pajeú; AM - Alto Moxotó; RC - Rio Capibaribe; Po - Riacho do Pontal; PEAL - Pernambuco-Alagoas; Sp - Sergipano; SFC - Cráton do São Francisco.

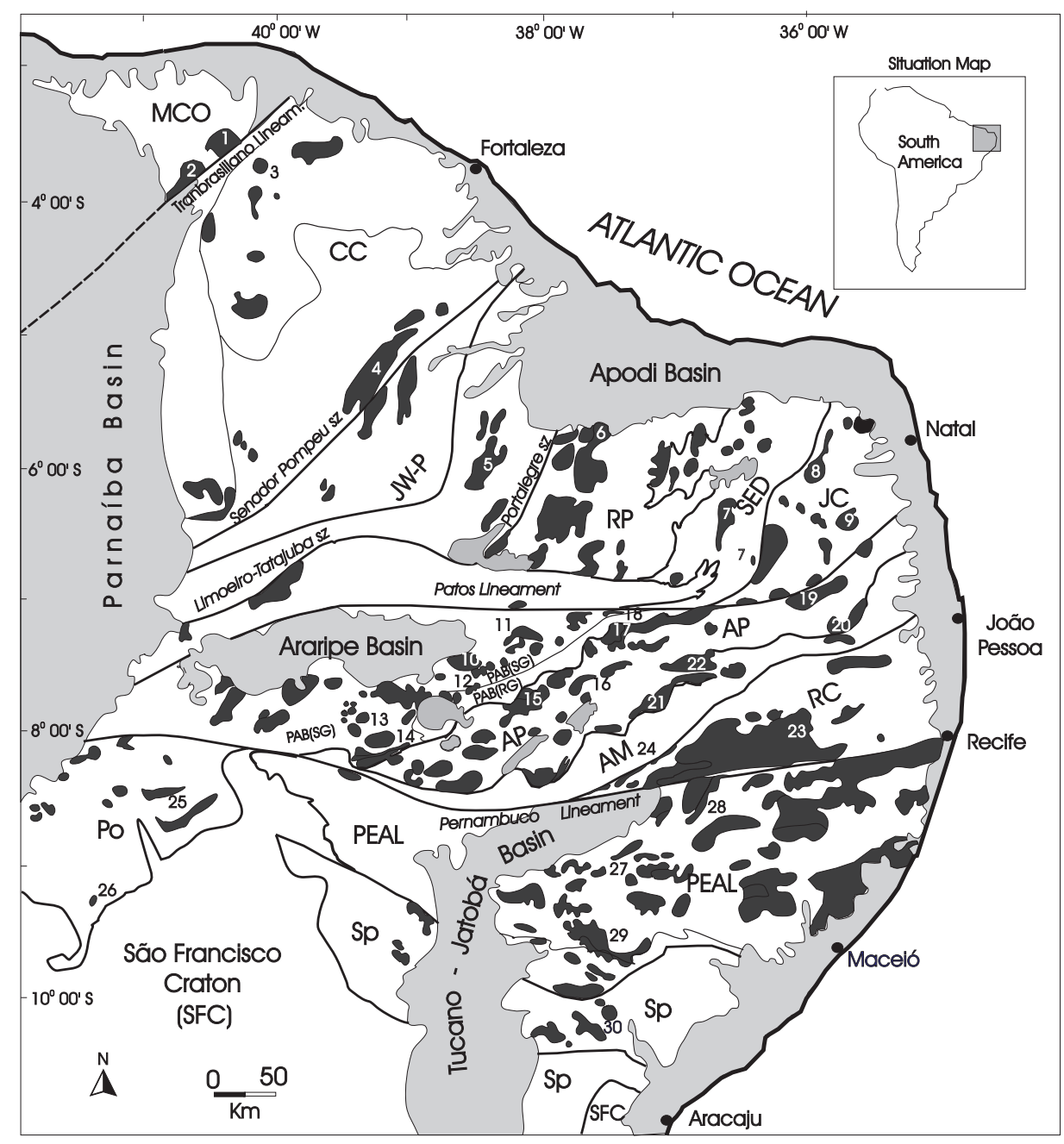


Os tipos graníticos discriminados naquela oportunidade para a área Caririana (designação então adotada para a Borborema) foram: os granitos sinorogênicos tipo Conceição (granodioritos e tonalitos) e Itaporanga (granitos ricos em fenocristais de microclina); granitos tardiorogênicos tipo Itapetim (granitos de granulação fina tardiorogênicos, de dimensões modestas e diques) e Catingueira (granitos peralcalinos, quartzo sienitos e sienitos); granitos pósorogênicos (granito a biotita da Serra da Meruoca); granito anorogênico (cretácico) do Cabo de Santo Agostinho.

Muito avanço nos conhecimentos pode ser registrado desde esse precioso início, que foi também deflagrador de várias frentes de pesquisas. O número de corpos conhecidos e estudados aumentou consideravelmente, nos três domínios principais da província, assim como as formas e técnicas de abordagem variaram bastante, em quantidade e em qualidade, com a adição das ferramentas da geoquímica (de rocha e de minerais), da geologia isotópica e até mesmo (em alguns casos), da geofísica, tudo isto sob o respaldo de um conhecimento bem mais evoluído (avanço substancial ocorreu no setor de mapeamento geológico regional) da geologia e da tectônica do conjunto.

Ainda assim, nas sínteses mais recentes que cobrem o progresso sobre o tema em epígrafe, de Ferreira et al. (1998, este precedido por sínteses de Sial et al., 1986, 1987) e de Santos \& Medeiros (1999, este reiterado quase integralmente em Brito Neves et al., 2000), as discriminações originais de Almeida et al. (1967) estão preservadas. Isto é importante acrescentar, ainda que estas tipologias tenham sido ampliadas e tenham tido seu conhecimento sobejamente enriquecido, tanto por subdivisão dos grupos inicialmente propostos, como pelo reconhecimento de novos grupos. E, também porque estas sínteses mencionadas são diferentes entre si em concepção, formas de abordagem e parâmetros gerais.

\section{GRANITOS DA BORBOREMA - SÍNTESES RECENTES}

Como preliminarmente exposto acima, a província em análise apresenta grande diversidade de granitos, nos seus três maiores domínios (setentrional, central/zona transversal e meridional/zona perifranciscana, vide Brito Neves et al., 2000), e nestes domínios em diferentes circunstâncias geológicas (natureza e idade de encaixantes) e estruturais (associadas ou não com zonas de falhas). Embora o progresso do conhecimento tenha sido expressivo nas últimas três décadas, as perspectivas de investigação científica sempre são crescentes (em termos do número e tipos de ocor- rências, e do método a adotar), de forma que qualquer tentativa de classificação sempre apresentará problemas, neste estágio de pleno fluxo do conhecimento. Já foi assinalado devidamente que em todas as classificações e sistematizações propostas, os tipos reconhecidos pelo trabalho de Almeida et al. (1967) permanecem, ainda que com desdobramentos.

A classificação proposta por Ferreira et al. (1998) é produto da evolução de várias propostas anteriores do mesmo grupo de pesquisas (Núcleo de Estudos de Granitos/NEG da Universidade Federal de Pernambuco), já sintetizadas por Sial (1986) e Sial et al. (1987). Consideram a província como um todo, em seus diferentes domínios, e nestes dentro do possível -, levando em conta (além de afinidades petrogenéticas, geoquímicas, estudos isotópicos, parâmetros de susceptibilidade magnética) a trama dos terrenos pré-Cambrianos. Estes autores ampliaram desta forma para nove os tipos de granitos reconhecíveis, entre os quais quatro tipos pelo menos de natureza cálcio-alcalina, a saber:

1. cálcio-alcalino normal (Conceição), com típico epidoto magmático;

2. cálcio alcalino de alto potássio sem epidoto magmático (tipo Itaporanga);

3. cálcio-alcalino de alto potássio com epidoto (Tipo São Rafael);

4. cálcio-alcalinos peraluminosos (tipo Ouro Branco);

5. trondhjemitos (tipo Serrita);

6. peralcalinos (Catingueira) e shoshoníticos (limites geoquímicos não bem definidos entre estes dois);

7. sienitóides metaluminosos de alto potássio (tipo Terra Nova);

8. sienitóides peralcalinos ultrapotássicos (tipo Triunfo/Baixa Verde).

Este trabalho acima referido é notável pelo acervo de dados petrográficos, geoquímicos e isotópicos (isótopos estáveis principalmente), discussão de protólitos e tentativa de identificação com os terrenos tectono-estratigráficos, porém não aborda frontalmente os modelos tectônicos, nem os propõe, embora se deva compreender o suporte multidisciplinar adicional que seria necessário.

As primeiras determinações U-Pb em zircão e dados isotópicos $\mathrm{Sm}-\mathrm{Nd}$ de parte desses granitos foram realizados por Guimarães et al. (1998), os quais apresentaram, na forma de resumo, uma classificação considerando composição mineralógica, afinidade geoquímica, natureza das 
encaixantes e dos possíveis protólitos, principalmente no contexto do domínio central da província, a Zona Transversal. Estes autores distinguiram 5 grupos, incluindo alguns tipos já identificados por Sial (1987) e por Ferreira et al. (1998), desde os mais antigos (644 -620 Ma) até os mais jovens $(540-520 \mathrm{Ma})$, a saber:

\section{1. cálcio-alcalinos normais;}

2. cálcio-alcalinos de alto potássio (com afinidades shoshoníticas);

3. sienogranitos, quartzo sienitos e sienitos com afinidades shoshoníticas;

4. biotita granitos (transicionais entre alcalinos e shoshoníticos);

5. biotita sienogranitos leucocráticos; biotita sienogranitos comagmáticos com basalto e dacitos (idades mais jovens).

A destacar, adicionalmente nesta classificação, as observações/sugestões de modelos tectônicos: para as primeiras quatro tipologias, os autores enfatizam as características de rochas relacionadas com evolução de arcos magmáticos, e para o último grupo apontaram localização do interior de placas litosféricas (altos valores de idade modelo, $\mathrm{T}_{\mathrm{DM}}$ ).

A proposição de Santos \& Medeiros (1999) aqui evocada (como já o fora em Brito Neves et al., 2000), procurou posicionar as diversas associações petrogenéticas e tipos de plútons (descritos previamente na literatura) utilizando os conceitos de suíte e supersuíte da escola australiana (ibiden Pitcher, 1993). De acordo com estes autores, a grande variedade de associações graníticas (pulsos, surges e suítes) pode ser englobada em três grandes supersuítes, considerando-se modelos petrogenéticos propostos e a colocação dessas suítes ao longo da colagem do Brasiliano. Apesar de persistirem dúvidas com respeito ao enquadramento de algumas associações petrogenéticas, esta classificação procurou ser a mais coerente possível com o quadro geotectônico regional, razão pela qual esta classificação está sendo reiterada neste trabalho. Foram identificadas três supersuítes:

a. suítes derivadas de fontes híbridas e crustais - abrange os principais eventos de plutonismo afetando a província, das fases contracionais iniciais até os movimentos finais de extrusão. Inclui os cálcio-alcalinos normais (Conceição), os cálcio alcalinos de alto potássio (Itaporanga), os cálcio alcalinos peraluminosos (Ouro Branco, Xingó e Rajada, crustais colisionais), os trondhjemíticos (composição granodiorítica e tonalítica) e os peralcalinos com aegirina- augita e anfibólios azuis (Catingueira), incluindo muitos outros corpos menores associados com as extensões laterais/ "feather faults" das grandes zonas de cisalhamento de Patos e de Pernambuco, a maioria dos quais já identificados desde Almeida et al. (1967), e que foram objeto da análises geocronológicas aqui apresentadas. Entre os dois primeiros tipos cálcio-alcalinos há tipos intermediários, onde a discriminação é problemática, ao nível de corpos e mesmo no interior polidiapírico de um mesmo corpo, além disso, é bastante provável que tenha havido mais de uma geração no tempo destas tipologias, o que é praticamente comprovado para os de alto potássio (há evidências de relações diretas no campo).

b. suítes derivadas de manto-enriquecido - abrangendo rochas sin-cinemáticas e tardi-cinemáticas às grandes zonas transcorrentes, aparentemente marcando descontinuidades crustais profundas (lineamentos de Patos e Pernambuco). A suíte cálcio-alcalina de alto potássio exibe rochas monzoníticas e monzograníticas, sendo seus principais representantes os batólitos de Esperança e Campina Grande (limite norte do terreno Alto Pajeú, da Zona Transversal) e o batólito de Fazenda Nova (norte do Lineamento Pernambuco, na Zona Transversal). Uma expressiva suíte shoshonítica-ultrapotássica foi colocada na Zona de Cisalhamento Fernandes Vieira, ao longo do limite dos terrenos Alto Pajeú e Piancó-Alto Brígida (interior da Zona Transversal/Domínio Central), o batólito sienítico de Triunfo, a aegirina-augita e richterita, com inclusões flogopitapiroxenitos, tendo fragmentos do manto litosférico (Ferreira, 1991) considerados como fonte do magma. Outros batólitos de natureza semelhantes são encontrados ao longo do alto tectônico Teixeira-Terra Nova e de outras zonas de cisalhamento expressivas. Os batólitos de Teixeira, Solidão e Serra Branca, incluídos nesta supersuíte, e em condições tectônicas semelhantes, foram considerados (em acordo com Guimarães et al., 1998); estas rochas sienograníticas, quartzo-monzoníticas e quartzo monzodioríticas são consideradas parte de uma suíte transicional shoshonítica-alcalina.

c. suítes híbridas, intrusivas graníticas menores e enxames de diques relacionados com as fases pós-colisionais. As principais áreas de ocorrência estão no noroeste do Ceará (Terrenos Médio Coreaú e Ceará Central), nas imediações dos lineamentos Sobral e Groaíras-Tauá. Estão incluídos os stocks de Meruoca (discriminado já no trabalho de Almeida et al., 1967), Mucambo e Serra da Barriga e um conjunto de diques de mesma idade. O corpo de Meruoca apresenta facies granítica e quartzo sienítica (com aegirina e riebeckita) e facies locais com faialita (Sial et al., 1981; Sial, 1989). O corpo de Mocambo consiste de granodiorito, granito e quartzo-sienito com hornblenda e biotita. No maciço do Rio Piranhas (granito de Umarizal) próximo de zona de cisalhamento 
(Portalegre, Frutuoso Gomes) e no maciço do S. José do Campestre (corpos de Dona Ignês e Monte das Gameleiras), assim como o Complexo de Prata (Guimarães et al., acima citados) há várias ocorrências que devem ser incluídas nesta supersuíte.

\section{PRO CEDIMENTOS ANALÍTICOS USUAIS (utilizados no CPGeo - USP)}

A concentração de minerais pesados foi feita através de mesa vibratória, seguindo-se separação magnética usando o aparelho Frantz e o tratamento em líquidos densos. O material não magnético é passado novamente no separador Frantz a 1,5 A com diferentes inclinações para obtenção de frações com susceptibilidades magnéticas distintas (split). Nesta etapa o material pode ser submetido à abrasão mecânica para eliminação das porções mais externas dos cristais, que contém alto teor em $\mathrm{Pb}$ comum. A purificação final das frações, preferencialmente as menos magnéticas, é realizada por catação manual sob lupa binocular. Após a pesagem (relação volume/ densidade), é realizada a lavagem com $\mathrm{HCl}$ e $\mathrm{HNO}_{3}$.

$\mathrm{O}$ ataque químico foi realizado com ácido fluorídrico (HF) e $\mathrm{HNO}_{3}$ em micro-bombas de Teflon, onde o conjunto, já com spike $\mathrm{Pb}^{205}(10 \mu \mathrm{l})$ é colocado em estufa a $200^{\circ} \mathrm{C}$, por três dias. A solução resultante, condicionada em $\mathrm{HCl}$, é então passada em colunas de troca iônica para separação e purificação do $\mathrm{U}$ e $\mathrm{Pb}$, através da lixiviação de outros elementos químicos por diferentes concentrações de $\mathrm{HCl}$. $\mathrm{O} \mathrm{U}$ e $\mathrm{Pb}$ são coletados com água MiliQ. A partir da solução final desta etapa adquire-se uma microgota que é depositada em filamentos de Re, para posterior leitura no espectrômetro de massa, que fornece as razões isotópicas. Utiliza-se o espectrômetro Finnigan MAT 262 com multicoletores, e os resultados obtidos são tratados em programas de software PbDAT (1993) e ISOPLOT de Ludwig (2001), para confecção dos diagramas.

\section{DETERMIN AÇÕES GEOCRONOLÓGICAS EFETUADAS}

\section{Granodiorito Conceição}

As rochas associadas a esta tipologia são típicas (mas não exclusivas) aflorando ao longo do Sistema Piancó-Alto Brígida, na porção centro-ocidental da Zona Transversal (também não exclusivamente) intrudindo rochas supracrustais metamórficas de baixo grau (Grupo Santana dos
Garrotes/Cachoeirinha e Complexo Riacho Gravatá).

Em geral, tratam-se de rochas de composição tonalítica a granodiorita, com biotita e hornblenda, e epidoto magmático. Apresentam de granulação média (alguns raros tipos de textura grossa a porfirítica) e com autólitos dioríticos e clots de anfibólio (vide Sial, 1986 e Sial et al., 1987), em número e dimensões bastante variáveis. São rochas metaluminosas a peraluminosas, cálcio-alcalinas tipo I, guardando muitas semelhanças gerais com aquelas de arcos magmáticos modernos (andes chilenos, por exemplo, batólitos costeiros). A farta bibliografia preexistente sobre estas ocorrências (e. g. Sial et al., 1997) deve ser consultada para detalhes adicionais de composição, barometria, razões isotópicas e fontes etc.

A amostra datada representa fração de composição granodiorítica, de granulação média, foi coletada na periferia da cidade topônima, cerca de $1 \mathrm{~km}$ ao norte do centro. Foram utilizados cristais de zircões prismáticos, com bi-terminação bem definida (Foto 1), razão comprimento/largura próximo de 4, transparentes, incolores, sem fraturas, e com marcante zoneamento magmático. Aidade obtida foi de $635 \pm 9( \pm 10)$ $\mathrm{Ma}$, dada pelo intercepto superior de uma discórdia de seis pontos, forçada através da origem (Figura 2), sendo interpretada como época de formação desta rocha.

Duas frações magnéticas de zircões, mais concordantes em relação às demais, apontam uma idade $c a$. de $570 \mathrm{Ma}$, podendo refletir algum evento térmico sobreposto que pode ter permitido a recristalização parcial dos cristais analisados. Tal possibilidade pode ser corroborada tendo em vista a existência de idades desta ordem e valor em outros eventos granitogênicos e tectônicos da região. A opção pelo valor de idade de $635 \mathrm{Ma}$ foi feita pelo maior número de pontos na corda e pela boa qualidade dos dados analíticos em geral, mas o ideal seria um aprofundamento na análise isotópica (utilização de SHRIMP, por exemplo). Adicionalmente, a idade de $635 \pm 9 \mathrm{Ma}$, interpretada como época de formação do granodiorito, é reiterada pela existência prévia de uma determinação Ar-Ar em anfibólio na ordem de 625 Ma (Dallmeyer et al., 1987).

Convém lembrar que o plúton de Conceição se situa na parte sul do batólito da Serra da Lagoinha formado por granitos do tipo Itaporanga, que exibem exemplos típicos de mecanismo de mistura e coexistência de magmas máfico e félsico, para os quais um modelo $M A S H$ foi sugerido por Santos \& Medeiros (1999). Assim sendo, em coerência com estas observações, pode ser levantada a hipótese de que a idade ca. 635 Ma represente uma herança do evento primário de colocação de magmas máficos e sua mistura com fundidos crustais, enquanto que a idade mais jovem poderia estar balizando a extração de um blend intrusivo subseqüente, conforme preconiza este modelo. 


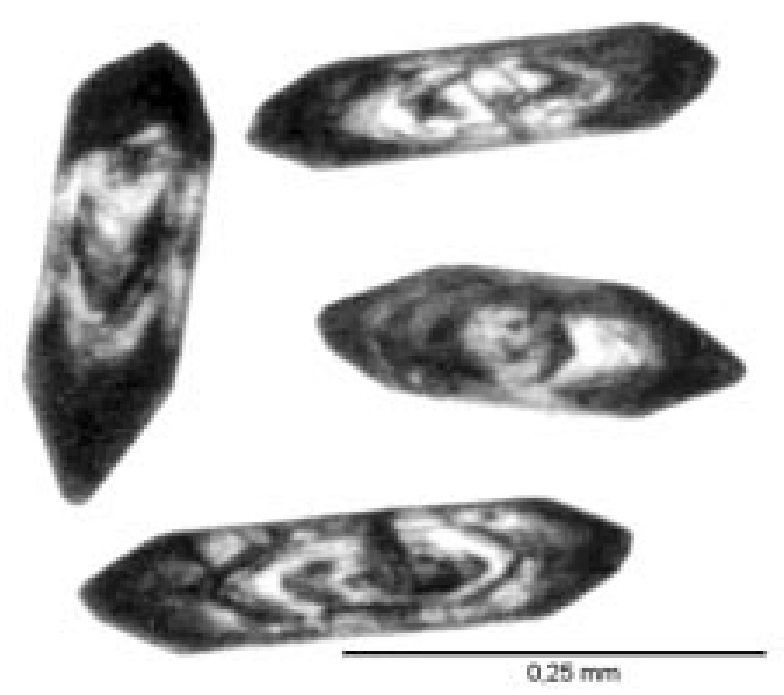

Foto 1. Imagem fotográfica dos zircões datados de Conceição.

Para uma amostra do mesmo corpo, foi obtida uma idade modelo $\mathrm{T}_{\mathrm{DM}}=1223 \mathrm{Ma}$, com valor de $\varepsilon_{\mathrm{Nd} 600}=-1,23$, o que pode ser inferido como resultante da participação importante de materiais juvenis no magma original, o que vem em acordo com a presença de fragmentos de metabasaltos (interpretado como material fonte, Ferreira et al., 1998, entre outros). Vide Tabela 1.

\section{Batólito de Tavares}

O Batólito de Tavares foi reconhecido como um corpo cálcio-alcalino de alto potássio, tipo Itaporanga, de há muito, e foi recentemente objeto de uma tese de doutoramento (Pessoa, 2002, inédito; Pessoa et al., 1999), sendo tratado nesta oportunidade por uma série de características geológicas especiais:

a. sua posição no alto estrutural (borda norte do Terreno Alto Pajeú, reativado no Terciário) Teixeira - Terra Nova, intrudindo ortognaisses Cariris Velhos (augen gnaisses tipo Ambó, eo-neoproterozóicos/Cariris Velhos) e contendo alguns enclaves deles;

b. a excepcional presença e preservação de estruturas magmáticas primárias (ladder dikes, snail, mushroom like, estruturas em bolhas, estruturas concêntricas, descritas por Weinberg et al., 2001);

c. do ponto de vista textural (porfiríticos com fenocristais de feldspato potássico) como o tipo Itaporanga, mas apresenta algumas características (contém epidoto magmático,

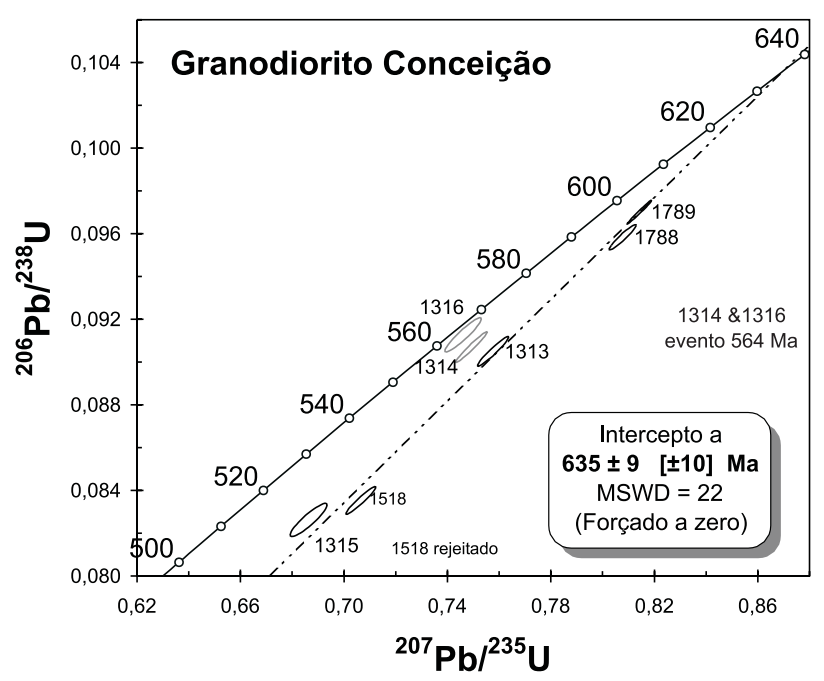

Figura 2. Diagrama discórdia para os zircões do granodiorito Conceição.

feições cedo-tectônicas/não deformadas) do tipo Conceição.

Sienogranitos, quartzo-sienitos, monzogranitos e quartzo-monzonitos são os litofacies predominantes, invariavelmente porfiríticos (cristais de feldspato potássico de até $20 \mathrm{~cm}$ ), com hornblenda, biotita e epidoto magmático, composição cálcio-alcalina de alto potássio, metaluminosa ou levemente peraluminoso (Pessoa et al., 1999).

A amostra foi coletada a cerca de $1 \mathrm{~km}$ oeste do centro da cidade de Tavares. Os cristais de zircão analisados são prismáticos (algumas arestas algo arredondadas), bi-terminação bem definida, razão comprimento/largura entre 2 e 4 , e excepcionalmente até 6 , são incolores, livres de fraturas e inclusões, com conspícuo zoneamento magmático (Foto 2). Cinco cristais mostram pontos analíticos na discórdia e indicam uma idade de $651 \pm 15$ ( $\pm 16 \mathrm{Ma}$ ), com o intercepto inferior forçado a origem (Figura 3). Este valor de idade foi apontado pelo intercepto superior, sendo interpretado como época de cristalização/formação desta rocha.

Uma isócrona $\mathrm{Rb}$-Sr foi traçada (CPGeo-USP, não publicado) para diversos tipos litológicos do Tavares, fornecendo uma isócrona de boa qualidade analítica na faixa de $590 \mathrm{Ma}$, considerado um valor mínimo de idade, relacionado ao fechamento do sistema $\mathrm{Rb}$-Sr. Outra vez estamos diante de dois valores de idades, para os quais se pode novamente evocar o caráter híbrido da associação tipo Itaporanga para tentar explicar esta dualidade de tempo. Em verdade, reiteramos que o valor de idade de 651 Ma está mais em acordo com o modelo MASH de Santos \& Medeiros (1999), anteriormente referido. 


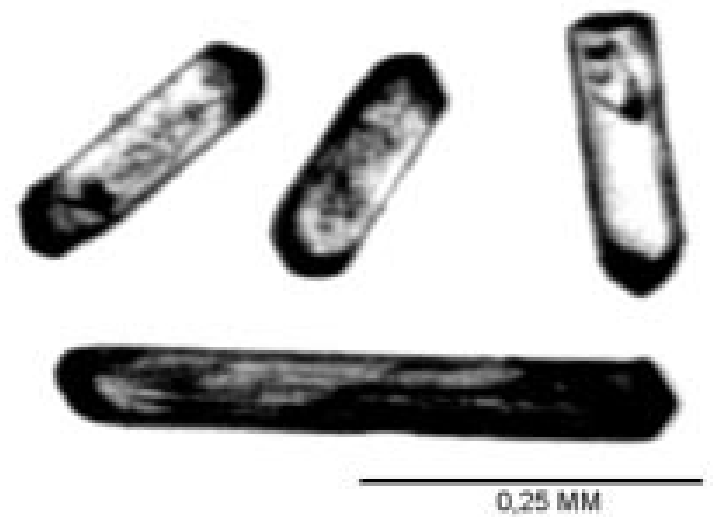

Foto 2. Imagem fotográfica dos zircões datados de Tavares.

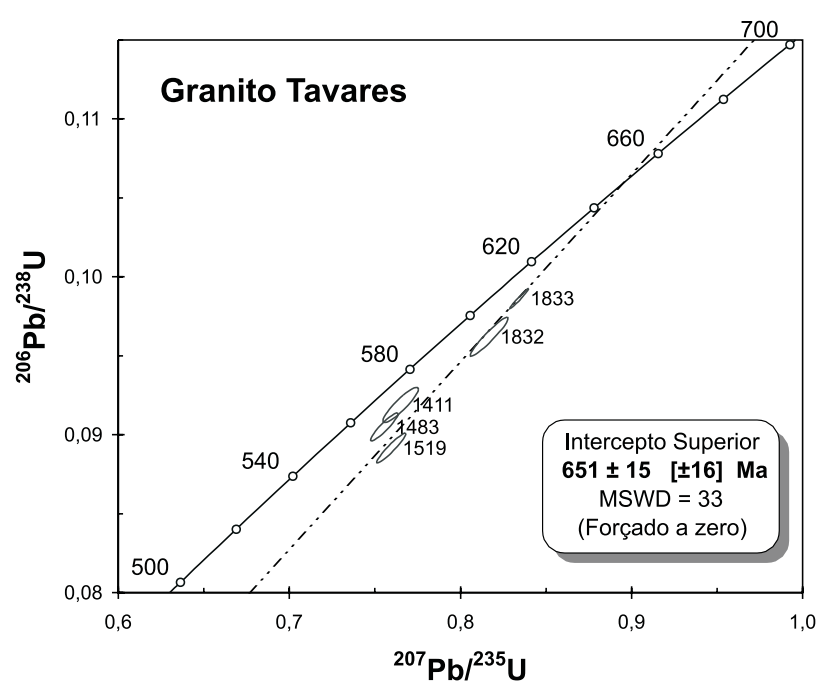

Figura 3. Diagrama discórdia para os zircões do granito de Tavares.

e mesmo de estruturas migmatíticas (estromáticas e agmáticas).

Um trabalho de petrologia e geoquímica, referência obrigatória para a localidade típica é a tese de Mariano (1989), assim como o trabalho de ASM de Archanjo et al. (1998).

As amostras para análise U-Pb foram coletadas na pedreira situada a $1,3 \mathrm{~km}$ leste da cidade de Itaporanga (na BR-361), na típica unidade porfirítica. Foram selecionados cristais de zircões prismáticos, tanto com arestas arredondadas como com bi-terminações bem definidas, normalmente translúcidos, mas que apresentavam inclusões e algumas fraturas (Foto 3). Foi obtido o alinhamento de muito boa qualidade de quatro pontos no diagrama discórdia para idade $\mathrm{T}=584,5+2 /-1,9$, para o intercepto inferior forçado a zero (Figura 4).

Este valor de idade, definido pelo intercepto superior, é compatível com dados Ar/Ar em hornblenda de $580 \mathrm{Ma}$ (Dallmeyer et al., 1987; Mariano, 1989), valor este considerado como idade mínima para a alocação do granito. Preexistem isócronas $\mathrm{Rb} / \mathrm{Sr}$ com valores de idade variáveis de $550 \mathrm{Ma}$ (inédita) e $620 \mathrm{Ma}$ (Mariano, 1989), mas todas elas com pequenos valores da razão $\mathrm{Rb} / \mathrm{Sr}$ e, portanto, qualitativamente de pouca expressão. Apesar disto, a dualidade de valores de idade - já ressaltada no trato dos granitos acima, volta a aparecer e reforçar as interpretações a ela já consignadas.

Da mesma pedreira foi coletada amostra para determinação $\mathrm{Sm}-\mathrm{Nd}$, que forneceu a idade $\mathrm{T}_{\mathrm{DM}}=1600 \mathrm{Ma}$ para $\mathcal{E}_{\mathrm{Nd} 600}=-9,0$, consignando assim a participação substancial de materiais continentais preexistentes (e retrabalhados) no e mingling, que também aparecem como enclaves máficos. Muito comum também é a presença de foliações metamórficas 


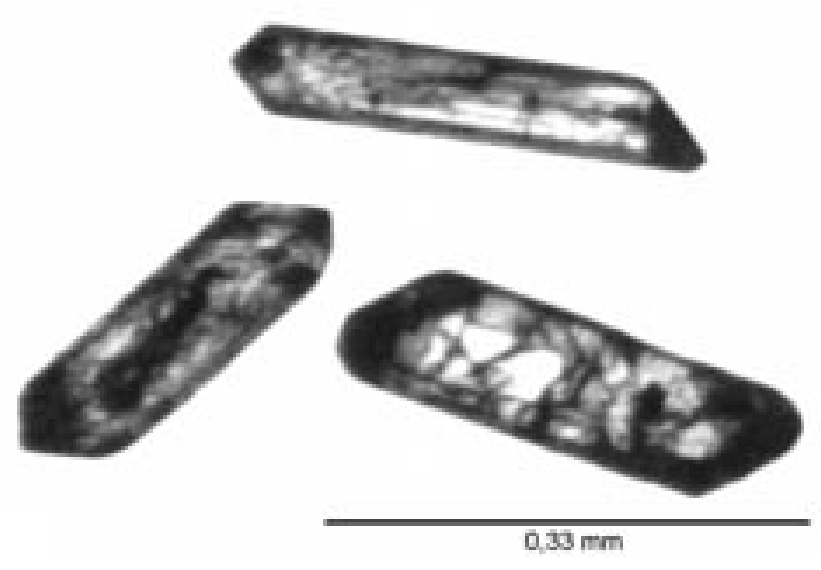

Foto 3. Imagem fotográfica dos zircões datados de Itaporanga.

protólito, o que é compatível com as observações na zona de contato (gradacional, ao norte, com rochas do embasamento paleoproterozóico).

\section{Granitóide Peralcalino de Catingueira}

O corpo de Catingueira tem forma tabular estreita e está colocado intrudindo rochas vulcano-sedimentares de baixo grau da Faixa Piancó-Alto Brígida (ao sul), sendo alongado na direção E-W (por cerca de $12 \mathrm{~km}$ ) em paralelo ao lineamento de Patos, segundo o qual desenvolve estreita faixa de milonitos. Composicionalmente trata-se de sienogranitos e monzogranitos alcalinos (Ferreira et al., 1998; Galindo \& Sá, 2000) com clinopiroxênios da série aegirina-augita (máficos dominantes) e com anfibólios da série riebeckitaarfverdsonita e biotita. Conforme pode ser observado em campo, e como consignado por Galindo \& Sá (2000), uma faixa de termometamorfitos (em torno de 1,5 km) é formada na auréola do corpo, com indicações mineralógicas do crescimento da temperatura no sentido do corpo ígneo (chegando a cordierita + sillimanita). O corpo de Catingueira apresenta foliação marcada pelos seus máficos, mas não de forma proeminente, de forma que estruturas ígneas primárias puderam ser preservadas nas partes mais internas.

Tratam-se de rochas extremamente enriquecidas em álcalis, e a classificação de peralcalinas já mencionada em itens anteriores é plenamente confirmada pelos estudos petrográficos e geoquímicos, em várias instâncias de diagramas analíticos de Galindo \& Sá (2000). Do ponto de vista

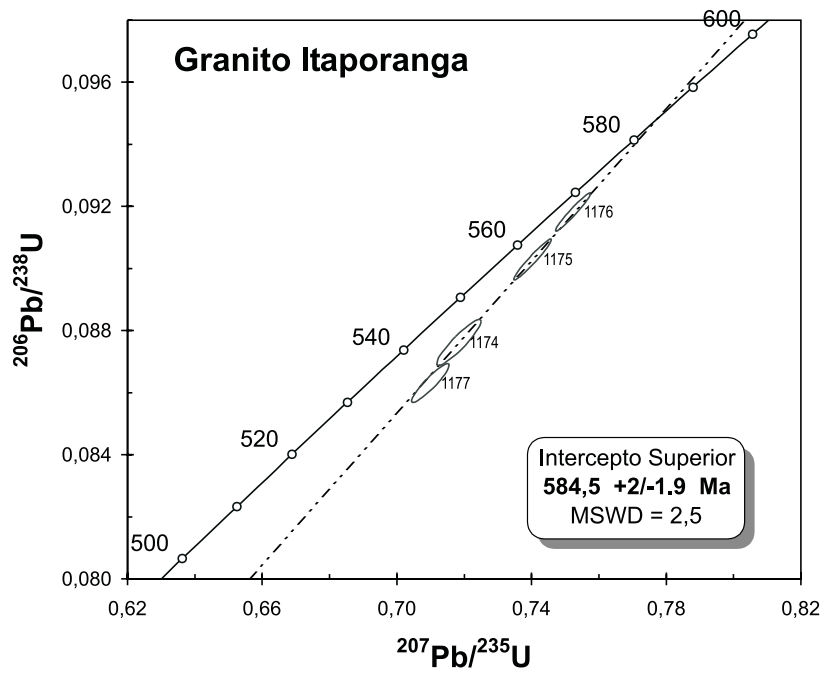

Figura 4. Diagrama discórdia para os zircões do granito de Itaporanga.

da discriminação de ambientes tectônicos obtida por estes autores aparece como notória a assinatura para granitos de arcos, indicações estas que são fato novo (e surpreendente, apesar do número pequeno de análises geoquímicas) para estes granitóides, consoantes as referências bibliográficas da Borborema (sempre foram consideradas de eventos tardi- a pós-orogênicos).

As amostras para as análises geocronológicas foram coletadas numa pedreira a cerca de $1 \mathrm{~km}$ a leste da cidade, na BR 230, em rocha leucocrática muito homogênea, de granulação média e composição sienogranítica. Os cristais de zircão são prismáticos, com razões comprimento/largura bastante variáveis, bi-terminação bem desenvolvida, transparentes, incolores (Foto 4), contendo algumas inclusões e microfraturas. Quando plotados em diagrama isotópico, as frações analisadas se mostraram bastante discordantes, indicando possibilidade de forte herança isotópica. $\mathrm{O}$ alinhamento de quatro pontos analíticos (Figura 5) definiu no intercepto inferior a idade $\mathrm{T}=573 \pm 45 \mathrm{Ma}$, com o intercepto superior indicando valores de idade superiores a $2150 \mathrm{Ma}$ (de várias interpretações possíveis, mas sempre com controvérsias). O erro de cerca de $10 \%$ no valor da idade é muito elevado, e serão necessários pontos adicionais para aprimoramento do resultado ora obtido.

Da mesma pedreira foi coletada amostra para análise $\mathrm{Sm} / \mathrm{Nd}$ que forneceu idade modelo $\mathrm{Tdm}=2397 \mathrm{Ma}$ para $\varepsilon_{\mathrm{Nd} 600}=-15,65$. Este valor encontrado, juntamente com o valor de idade apontado pelo intercepto superior da discórdia, abre várias possibilidades de discussão (contribuição importante de protólitos paleoproterozóicos??) que deman- 


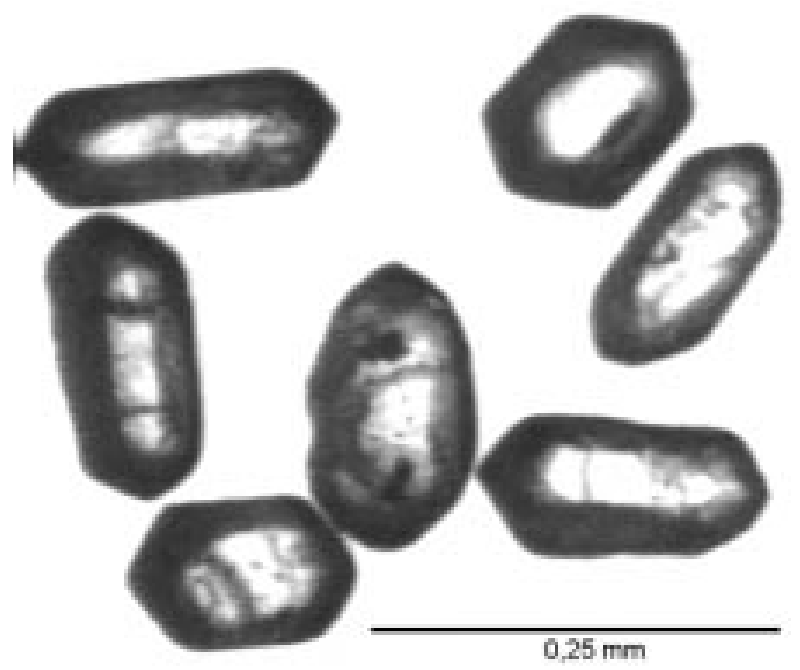

Foto 4. Imagem fotográfica dos zircões datados de Catingueira.

dam estudos adicionais. As indicações petrogenéticas requerem uma fonte anidra de caráter mantélico ou de base de crosta para a origem do magma deste granitóide (Galindo \& Sá, op. cit.), em ambiente de arco, ao mesmo tempo em que os dados isotópicos indicam uma forte contaminação crustal.

Preexiste uma determinação $\mathrm{K} / \mathrm{Ar}$ em piroxênios deste corpo granítico peralcalino, com $(\mathrm{T}=1200 \pm 220 \mathrm{Ma}$, CPGeo-USP), olhada com reservas, em vista da baixa qualidade analítica.

\section{Granitos de Meruoca e Mocambo (Supersuíte III)}

Estas rochas intrusivas do Noroeste do Ceará, nas imediações do Lineamento Sobral-Pedro II/Transbrasiliano (e da Bacia de Jaibaras) já haviam sido pinçadas como postorogenic granites desde o clássico trabalho de Almeida et al. (1967).

O batólito de Meruoca apresenta uma facies granítica avermelhada (brick) e uma facies cinzenta a faialita, e foi estudado por vários autores nas últimas décadas, destacando-se a tese de Sial (1989), como o trabalho mais completo do ponto de vista petrológico. A composição é majoritariamente granítica, com porções de alcali-feldspato granito e de quartzo sienitos subalternas.

$\mathrm{O}$ autor sênior obteve uma isócrona $\mathrm{Rb}-\mathrm{Sr}$ de $\mathrm{T}=520 \pm 6 \mathrm{Ma}(\mathrm{n}=4$, razão inicial de 0,706 , em trabalho inédito). Sial et al. (1981) obtiveram - para um conjunto de

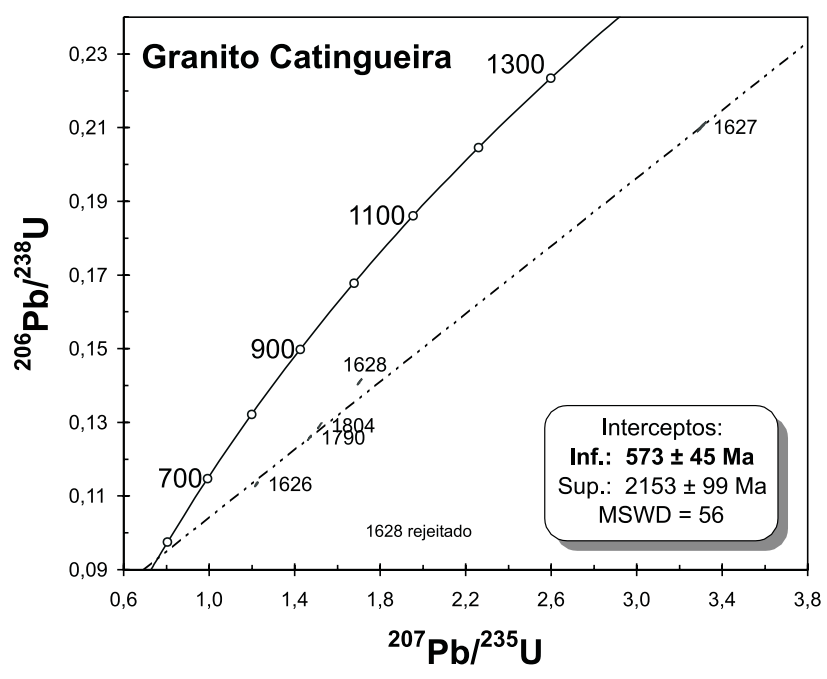

Figura 5. Diagrama discórdia para os zircões do granitóide peralcalino de Catingueira.

14 amostras do granito Meruoca -, com determinações $\mathrm{Rb}$-Sr em rocha total uma idade $\mathrm{T}=491 \pm 19$ (razão inicial $0,707 \pm 0,00028$ ). Mas, em ambos os casos, os autores observaram distúrbios no sistema $\mathrm{Rb}$-Sr, e colocaram pendências nas retas isocrônicas obtidas, deixando claro a necessidade de novas técnicas analíticas.

Mais recentemente, Fetter (1999) encontrou uma série de dificuldades (qualidade, formas e imperfeições nos zircões) para determinar a idade do granito pelo método $\mathrm{U}-\mathrm{Pb}$, para o qual, os dados $\mathrm{Rb}-\mathrm{Sr}$ servem de referencial, assim como a idade obtida no Mucambo.

O granito de Mucambo é geralmente de granulação grosseira até porfirítico, com a presença característica de muitos autólitos (quatzo-dioríticos e gabróides) e xenólitos de rochas encaixantes (Grupo Ubajara), além de exibir bem marcada auréola de metamorfismo de contato. Composicionalmente, predominam granitos, com biotita e hornblenda, e com composições de granodioritos e quartzo sienitos subordinadas.

Sial et al. (1981) apresentaram uma isócrona Rb-Sr para o Mucambo com idade de $548 \pm 24 \mathrm{Ma}$ (razão inicial $0,710 \pm 0,0011$ ), para um conjunto de seis determinações. Para esta rocha, Fetter (1999) obteve uma discórdia U-Pb indicando valor de idade de $532 \pm 6$ Ma no intercepto superior, de muito boa qualidade, além de ter obtido uma idade Ar-Ar de $527 \pm 3$ Ma. Estes valores de idades são de qualidade suficiente para indicar os eventos extrusionais do Ciclo Brasiliano dentro do Cambriano, e estes valores de idades são reforçados por outras indicações isotópicas, no Ceará 
(domínio setentrional da província) e fora dele (como por exemplo, os dados Ar-Ar disponíveis na Zona Transversal).

\section{CONCLUSÕES PRELIMINARES}

O cotejo entre os dados geocronológicos preexistentes em rochas graníticas da Província Borborema e aqueles aqui discutidos permitem esboçar um quadro muito preliminar da evolução regional (Quadro 1), consistente na escala de reconhecimento. Os dados aqui computados vêm reiterar fortemente valores de idades muito próximos daqueles intervalos principais de preconizados para as três supersuítes (I - 630 - 620 Ma; II - ca. 590 Ma; III - ca. 512 Ma) de Santos $\&$ Medeiros (1999). Os intervalos propostos por estes autores são considerados e revisados com o refinamento que se segue.

Dois intervalos de tempo do Neoproterozóico III - ca. 650 - 625 Ma (Eo-Neoproterozóico III) e ca. 580 - 570 Ma estão sendo sinalizados na maioria das determinações como marcadores de eventos de formação de granitos, ligados com interação acrescionária de placas litosféricas. Uma terceira etapa/estágio de formação de rochas graníticas se estende do final do Neoproterozóico III para a primeira metade do Cambriano (de $c a .545$ para $520 \mathrm{Ma}$ ), onde as ocorrências graníticas são muito variadas em composição, e estão vinculadas com processos extrusionais (sobretudo) e outros de natureza intraplacas.

A presença de eventos acrescionários graníticos bem mais precoces (e.g. $750 \pm 20 \mathrm{Ma}$, Riacho do Icó, Floresta PE, Santos, 1995; > 665 Ma, oeste do Ceará, Fetter et al., 2002) é uma possibilidade, com poucos dados ainda, e que deve ser explorada em programas de investigação complementares. Estes processos precoces podem ter ocorrido, tendo em vista informações geológicas e geocronológicas outras, bastante seguras (Brito Neves et al., 2000), de que eventos de extensão e tafrogênese significativa (e provável fissão) foram consignados desde $c a .800 \mathrm{Ma}$. De forma que uma história delongada (e diacrônica) pode ser preconizada para a colagem da província como um todo, com eventos distribuídos ao longo de $300 \mathrm{Ma}$ (Cedo-Brasiliano para PósBrasiliano), do Neo-Toniano para o Cambriano.

Diante da complexidade e das dimensões do problema da granitogênese na Borborema, os dados aqui apresentados constituem uma contribuição pequena, mas valiosa e digna de registro, podendo alicerçar e servir de referência para as etapas seguintes do avanço do conhecimento.

Quadro 1. Principais determinações geocronológicas (Ma) de rochas graníticas da Província Borborema (Pb- $\mathrm{Pb}$ e U- $\mathrm{Pb}$ ). Afora os dados ora introduzidos (e sinalizados \#), os demais dados devem ser consultados na bibliografia (todos estão referendados devidamente, vide Referências Bibliográficas).

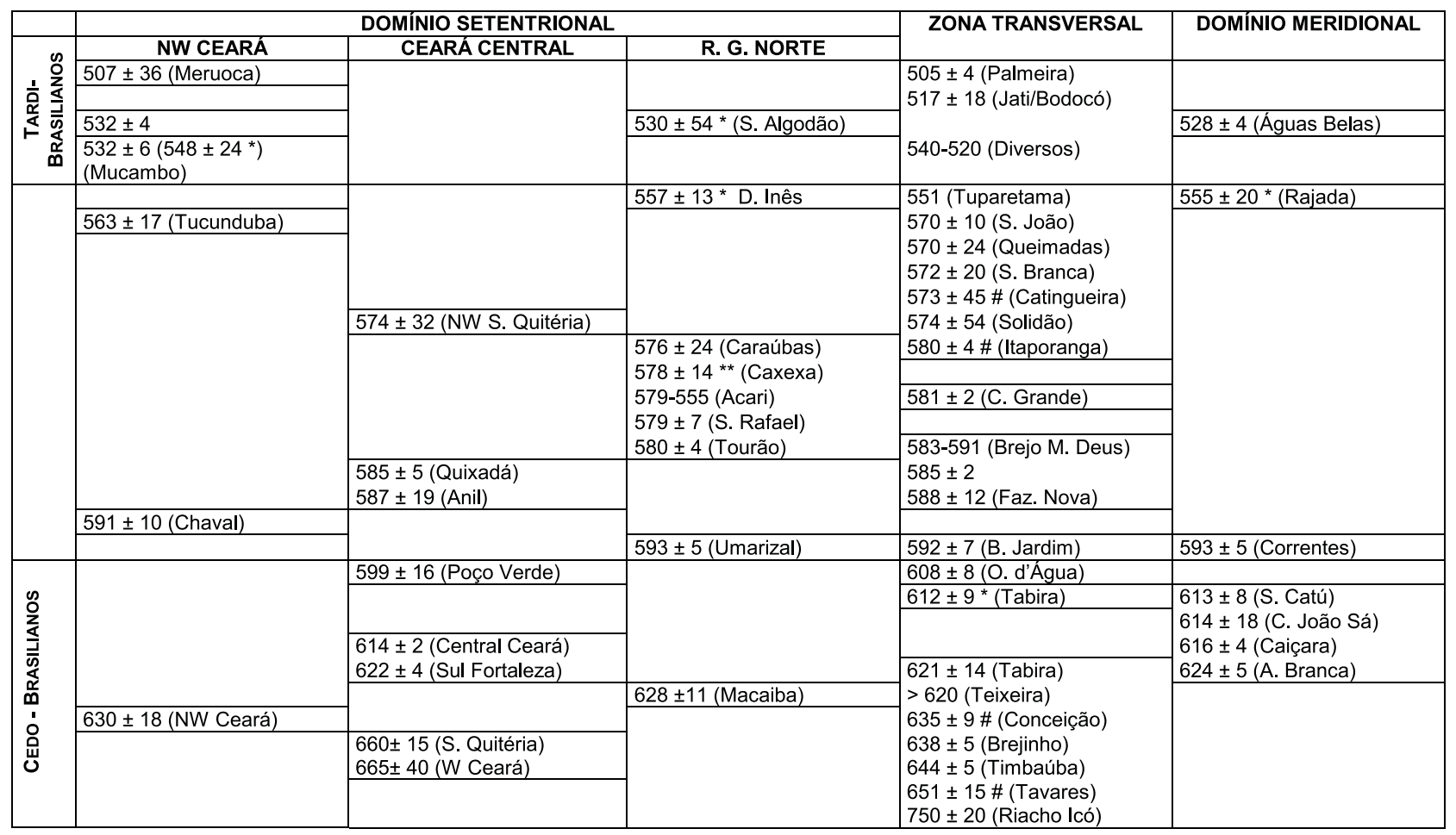

* Datação Rb/Sr; ** Datação Sm/Nd; \# Neste trabalho. 
Tabela 1. Dados analíticos das determinações U-Pb relativos aos diagramas das Figuras 2 a 5.

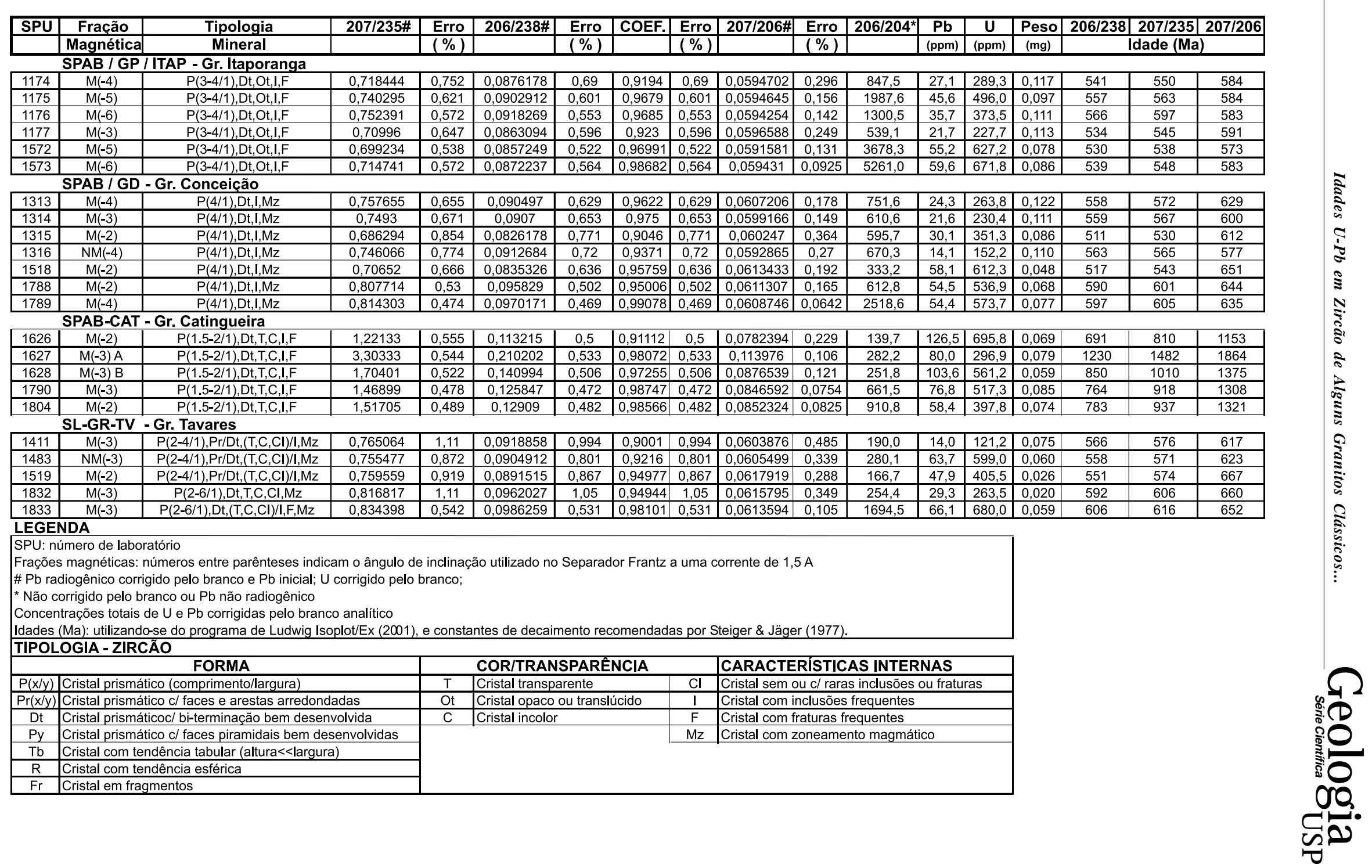




\section{REFERÊNCIAS BIBLIOGRÁFICAS}

ALMEIDA, F. F. M.; LEONARDOS JR., O. H.; VALENÇA, J. (1967) Granitic rocks of Northeast South America. In: INTERNATIONAL UNION OF GEOLOGICAL SCIENCES, Recife, 1967. Recife, IUGS/UNESCO. 37 p.

ALMEIDA, N. C.; GUIMARÃES, I. P.; SILVA FILHO, A. F. (2002) A-type post-collisional granites in the Borborema Province - NE Brazil - the queimadas pluton. Gondwana Research, v. 5, n. 3, p. 667-681.

ALMEIDA, N. C.; GUIMARÃES, I. P.; SILVAFILHO, A. F.; BEURLEN, H. (1997) Sm-Nd isotope geochemistry and $\mathrm{U} / \mathrm{Pb}$ geochronological data of the Campina Grande Complex, Paraíba State, NE Brazil. In: SIMPÓSIO DE GEOLOGIA DO NORDESTE, 17., Fortaleza. Resumos Expandidos. Fortaleza, SBG-NO. Boletim n. 15, p. 3-6.

ARCHANJO, C. J.; SILVA, E. R.; CABY, R. (1999) Magnetic fabric and pluton emplacement in a transpressive shear zone system: the Itaporanga porphyritic granitic pluton (northeast Brazil). Tectonophysics, v. 312, p. 331-345.

BORGES, S. V. (1996) Geologia da região do Médio Curimataú $(P B)$ e o alojamento do Granito de Dona Inês associado a zonas de cisalhamentos transcorrentes brasilianas. São Paulo, 139 p. Dissertação (Mestrado) Instituto de Geociências, Universidade de São Paulo.

BRITO NEVES, B. B.; SANTOS, E. J.; VAN SCHMUS, W. R. (2000). Tectonic History of the Borborema Province. In: CORDANI, U. G.; MILANI, E. J.; THOMAZ FILHO, A.; CAMPOS, D. A . (eds.) Tectonic evolution of SouthAmerica. Rio de Janeiro, p. 151-182.

CASTELLANA, C. H.; LONG L. E.; SIAL, A. N. (2000) Origin of the Coronel João Sá Pluton: implications for the tectonic evolution of NE Brazil. In: INTERNATIONAL GEOLOGICAL CONGRESS, 31., Rio de Janeiro, 2000. $A b$ stracts. Rio de Janeiro. (CD-ROM).

DALLMEYER, R. D.; SIAL,A. N.; LONG, L.E.; Mc MURRY, J. (1987). New evidence for polyphase tectonothermal evolution of the Brasiliano Orogeny, northeastern Brazil. In: GEOLOGICALSOCIETY OFAMERICAANNUAL MEETING PHOENIX-ARIZONA, 1987. Abstracts with Program. Phoenix, Arizona, p. 634.

DANTAS,E.L.(1997) Geocronologia U-Pb e Sm-Nd de Terrenos Arqueanos e Paleoproterozóicos do Maciço Caldas Brandão, NE do Brasil. Rio claro-SP, 209 p. Tese (Doutorado) - Instituto de Geociências, Universidade Estadual Paulista.

FERREIRA, V. P. (1991) Petrology and geochemistry of Late Proterozoic ultrapotassic peralkaline Triunfo batholith and related dikes, State of Pernambuco, Northeast Brazil. Athens, 269 p. Tese (Doutorado) - Department of Geology, University of Georgia.

FERREIRA, M. A. F.; FERREIRA, V. P.; SIAL, A. N.; PIMENTEL, M. M. (2002) Origin and intensive parameters in the crystallization of ultrapotassic syenites: The Serra do Man Pluton, Northeastern Brazil. Gondwana Research, v. 5, n. 2, p. 275-285.

FERREIRA, V. P.; SIAL, A. N.; JARDIM DE SÁ, E. F. (1998) Geochemical and isotopic signatures of Proterozoic Granitoids in terranes of the Borborema structural province, northeast Brazil. Journal of South American Earth Sciences, v. 11, n. 5, p. 438-455.

FETTER, A. H. (1999) U/Pb and Sm/Nd geochronological constraints on the crustal framework and geological history of the Ceará State, NW Borborema Province, NE Brasil: Implications for the assembly of Gondwana. Lawrence, 164 p. Tese (Doutorado) - Department of Geology of the Faculty of the Graduate School, University of Kansas, Campus de Lawrence.

FETTER, A. H.; SANTOS, T. S.; VAN SCHMUS, W. R.; HACKSPACHER, P. C.; BRITO NEVES, B. B.; ARTHAUD, M.H.; NOGUEIRANETO, J.A.; WERNICK, E. (2002) Evidence for Neoproterozoic rifting and subsequent convergence along the northwest margin of the Borborema province, Ceará State, NE Brazil: implications for the breakup of Rodinia and the assembly of West Gondwanan. In: INTERNATIONAL GONDWANASYMPOSIUM, 11., Christchurch, New Zealand, 2002. Correlations and Connections. New Zealand, University of Canterbury.

GALINDO, A. C.; SÁ, J. M. (2000) Contexto tectônico e geoquímico do granitóide Catingueira: um magmatismo alcalino-peralcalino no limite norte da Zona Transversal da Província Borborema. Geochimica Brasiliensis, v. 14, n. 1, p. 1-21.

GUIMARÃES, I. P.; ALMEIDA, C. N. (2001) The Calk-alkaline Brasiliano granitoids in the Pajeú-Paraíba belt, Northeast Brazil: the Timbaúba Complex. In: SIMPÓSIO DE GEOLOGIA DO NORDESTE, 19., Natal. Resumos. Natal, SBG-NO. Boletim n. 17, p. 232-233.

GUIMARÃES, I. P.; SILVAFILHO,A. F. (2000) Evidence of multiple involved sources in the genesis of the neoproterozoic Itapetim Granitic Complex, NE Brazil, based on geochemical and isotopic data. Journal of South American Earth Sciences, v. 13, p. 561-586.

GUIMARÃES, I. P.; SILVAFILHO, A. S . (2000) Caracterização geoquímica e isotópica do Complexo Granítico de Itapetim-PE. In: SIMPÓSIO DE GEOLOGIA DO NOR- 
DESTE, 18., Recife, 2000. Resumos. Recife, SBG-NO. Boletim n. 16, p. 96.

GUIMARÃES, I. P.; SILVA FILHO, A. F.; ALMEIDA, C. N.; ARAÚJO, J. M. M.; SALES, A.; MELO, S. C. (1998) The Brasiliano granitoids from the Pajeú-Paraíba belt and Teixeira High: $\mathrm{Sm}-\mathrm{Nd}$ isotope geochemistry and $\mathrm{U}-\mathrm{Pb}$ in zircon ages. In: CONGRESSO BRASILEIRO DE GEOLOGIA, 40., Belo Horizonte, 1998. Anais. Belo Horizonte, SBG, p. 48 .

JARDIM DE SÁ, E . F. (1994) A faixa Seridó (Província Borborema, Nordeste do Brasil) e o seu significado geodinâmico na Cadeia Brasiliana/Pan-africana. Brasília, 804 p. Tese (Doutorado) - Instituto de Geociências, Universidade de Brasília.

JARDIM DE SÁ, E. F.; MACEDO, M. H .F.; KAWASHITA, K.; PEUCAT, J. J.; LETERRIER, J.; FUCK, R. A. (1996) A suíte Serra da Esperança: intrusões alcalinas sintectônicas aos nappes brasilianos da Faixa Riacho do Pontal. In: CONGRESSO BRASILEIRO DE GEOLOGIA, 39., Salvador, 1996. Anais. Salvador, SBG, v. 6, p. 499-501.

JARDIM DE SÁ, E. F.; TRINDADE, R. I. F.; HOLLANDA, M. H. B. M. ; ARAUJO, J. M . M.; GALINDO, A.C.; AMARO, V.; SOUZA, Z.; VIGNERESSE, J.L.; LARDEAUX, J. M. (1999) Brasiliano syntectonic alkaline granites emplaced on a strike-slip/extensional setting. Anais da Academia Brasileira de Ciências, v. 71, n. 1, p. 17-28.

KOZUCH, M. (2003) Isotopic and trace elements Geochemistry of early Neoproterozoic gneissic and metavolcanic rocks in the Cariris Velhos Orogen of the Borborema Province, Brazil and their bearing on tectonic setting. Lawrence, Kansas, 199 p. Tese (Doctor of Philosophy) - Department of Geology, the University of Kansas, Kansas.

KOZUCH, M.; BITTAR, S. M. B.; VAN SCHMUS, W. R.; BRITO NEVES, B. B. (1997) Late mesoproterozoic and middle neoproterozoic magmatism in the zona transversal of Borborema Province, Brazil. In: SIMPÓSIO DE GEOLOGIA DO NORDESTE, 17., Fortaleza. Resumos Expandidos. Fortaleza, SBG-NO. Boletim n. 15, p. 47-50.

LEGRAND, J. M.; DEUTSCH, S.; SOUZA, Z. (1991) Datação $\mathrm{U} / \mathrm{Pb}$ e granitogênese do Maciço Acari (RN). In: SIMPÓSIODE GEOLOGIA DO NORDESTE, 14., Recife, 1991. Atas. Recife, SBG-NO. Boletim n. 12, p. 172-173.

LEITE,P.R. B.; BERTRAND, J. M.; LIMA, E. S.; LETERRIER, J. (2000) Timing of granitic magmatism in the northern Borborema Province, Brazil: a U-Pb study of granitoids from Alto Pajeú Terrain. Journal of South American Earth Sciences, v. 13, p. 549-559.
LETERRRIER, J.; JARDIM DE SÁ, E. F.; BERTRAND, J. M.; PIN, C. (1994) Ages U-Pb sur Zircon de granitoïdes "brasilianos" de la ceinture du Seridó (province Borborema, NE Brésil). Compte Rendu Academie des Sciences Paris. Série II, v. 318, p. 1505-1511.

LUDWIG, K. R. (2001) Isoplot/Ex, rev. 2.49. kludwig@bgc.org MARIANO, G. (1989) Magma mixing origin of a Potassic Calc-alkaline pluton. The Itaporanga Batholith, State of Paraiba, Northeast Brazil. Athens, 180 p. Tese (Doutorado) - Graduate Faculty of the University of Georgia, Georgia.

McREATH, I.; GALINDO, A. C.; DALL 'AGNOL, R. (2002) The Umarizal igneous association, Borborema Province, NE Brazil: implications for the genesis of a-type granites. Gondwana Research, v. 5, n. 2, p. 339-353.

MELO, E. B.; GUIMARÃES, I. P. (1995) Os granitóides póstectônicos a sul da Zona de cisalhamento de Afogados de Ingazeira-PE. In: SIMPÓSIO DE GEOLOGIA DO NORDESTE, 15., Recife, 1995. Atas. Recife, SBG-NO. Boletim n.14, v. 1, p. 287-289.

MELO, S.; NEVES, S. P.; SILVA, J. M. R.; MARIANO, G. (2000) Petrografia e geoquímica do Batólito Brejo da Madre de Deus/Pernambuco-NE/Brasil. In: SIMPÓSIO DE GEOLOGIA DO NORDESTE, 18., Recife. Resumos. Recife, SBG-NO. Boletim n. 16, p.100.

MELO, S.; NEVES, S. P.; SILVA, J. M. R..; MOURA, C. (2000) Geocronologia $\mathrm{Pb}-\mathrm{Pb}$ no Batólito Brejo da Madre de Deus/Pernambuco, Nordeste do Brasil. In: SIMPÓSIO DE GEOLOGIA DO NORDESTE, 18., Recife. Resumos. Recife, SBG-NO. Boletim n. 16, p.101.

NASCIMENTO, M. A. L.; SOUZA, Z. S.; NASCIMENTO, R. S. C.; GALINDO, A. C.; HOLLANDA, M. H. B. M.; PIMENTEL, M.M.; MACEDO, M. F. H . (2000) In: SIMPÓSIODE GEOLOGIADO NORDESTE, 18., Recife. Resumos. Recife, SBG-NO. Boletim n. 16, p.102.

NASCIMENTO, M . A. L.; SOUZA, Z. ; GALINDO, A. C. (2000) Magmatismo granítico de série alcalina na extremidade oriental da Província Borborema - o plúton Caxexa: Geologia e Geoquímica. Geochimica Brasiliensis, v. 14, n. 1, p. 23-40.

NASCIMENTO, M.A.L.; SOUZA, Z.; HOLLANDA, M. H. B . M.; PIMENTEL, M. M.; MACEDO, M. H. F.; NASCIMENTO, R. S. C.; GALINDO, A. C. (2001) Geocronologia e assinatura isotópica $\mathrm{Rb}-\mathrm{Sr}$ e $\mathrm{Sm}-\mathrm{Nd}$ do magmatismo alcalino Neoproterozóico no Maciço São José do Campestre, Nordeste do Brasil, Província Borborema. Estudos Geológicos. Série B, v. 11, p. 67-79.

NUTMAN, A. P. (2001) Relatório de atividades sobre determinações SHRIMP realizadas na Austrália - Progress 
report. São Paulo, Centro de Pesquisas Geocronológicas do Instituto de Geociências da Universidade de São Paulo.

PESSOA, R. J. R. P. (2001) Mecanismos de alojamento e construção do batólito granítico neoproterozóico de Tavares, Estado da Paraíba-Nordeste do Brasil. Recife, 218 p. Tese (Doutorado) - Centro de Tecnologia e Geociências, Universidade Federal de Pernambuco.

PESSOA, R. J. R.; SIAL, A. N.; FERREIRA, V. P. (1999) Upward transport of magmatic epidote in the Neoproterozoic high-K calc-alkalic Tavares Pluton, Alto Pajeú Terrane, NE Brazil . In: HUTTON SYMPOSIUM, 4., Clermont-Ferrrand, 1999. Abstracts. Clermont-Ferrand, France, p. 60.

SÁ, J. M. (1991). Evolution geodynamique de la ceinture proterozoique d'Orós, Nord-Est du Brésil. Nancy, 177 p. Tese (Doutorado) - Université de Nancy I, Faculté de Sciences, Laboratoire de Petrologie.

SAMPAIO, M. A. F.; SILVA FILHO, A. F.; GUIMARÃES, I. P. (2000) Geoquímica Isotópica e geocronologia do plutão neoproterozóico Água Branca, borda sul do Maciço PEAL, Província Borborema. In: SIMPÓSIO DE GEOLOGIA DO NORDESTE, 18., Recife, 2000. Resumos. Recife, SBG-NO. Boletim n. 16, p.111.

SANTOS, E. J. (1995) O complexo Granítico Lagoa das Pedras: acresção e colisão na região de Floresta (Pernambuco), Província Borborema. São Paulo, 220 p. Tese (Doutorado) - Instituto de Geociências, Universidade de São Paulo.

SANTOS, E. J.; MEDEIROS, W.C. (1999) Constraints from granitic plutonism on Proterozoic crustal growth of the Transverse Zone, Borborema Province, NE Brazil. Revista Brasileira de Geociências, v. 29, n. 1., p. 73-84.

SANTOS, E. J.; VASCONCELOS, M. L. S. (1973) Características dos granitóides de tipo moderna do lineamento Pernambuco. Revista Mineração Metalurgia, n. 339, p. 28-33.

SIAL, A. N. (1989) Petrologia, Geoquímica de elementos maiores, traços, Terras Raras e isótopos $(\mathrm{Sr}, \mathrm{O}, \mathrm{H}, \mathrm{S})$ nos batólitos de Meruoca e Mocambo, Ceará, Nordeste do Brasil. Recife, 284 p. Tese (Professor-Titular) Departamento de Geologia, Universidade Federal de Pernambuco.

SIAL, A. N. (1986) Granite-types in Northeast Brazil: current knowledge. Revista Brasileira de Geociências, v. 16, n. 1, p. 54-72.

SIAL, A. N.; FERREIRA, V. P.; MARIANO, G. (1987) Proterozoic granitoids, Western Pernambuco and Paraíba States, Northeast Brazil. In: INTERNATIONAL SYM-
POSIUM ON GRANITES AND ASSOCIATED MINERALIZATIONS, 1., Salvador, 1987. Excursion Guides. Salvador, SGM/CBPM, p. 9-32.

SIAL, A. N.; FERREIRA, V. P.; SANTOS, E. J. (1997) Magmatic epidote-bearing granitoids and ultrapotassic magmatism of the Borborema Province, Northeast Brazil. In: INTERNATIONALSYMPOSIUM ON GRANITES AND ASSOCIATED MINERALIZATIONS, 2., Salvador, 1997. Excursions Guides. Salvador, SGM/CBPM, p. 35-54.

SIAL, A. N.; FIGUEIREDO, M. C. H.; LONG, L. (1981) RareEarth element geochemistry of the Meruoca and Mucambo plutons, Ceará, Northeast Brazil. Chemical Geology, v. 312, p. 271-283.

SILVAFILHO, A. F.; GUIMARÃES, I . P.; SIQUEIRA, D.V. (1998) Evidências de manto sublitosférico enriquecido e suas conseqüências geotectônicas; o complexo shoshonítico neoproterozóico Serra do Catú, interface entre o maciço PE-AL e o Sistema de Dobramentos Sergipano. In: CONGRESSO BRASILEIRO DE GEOLOGIA, 40., Belo Horizonte, 1998. Anais. Belo Horizonte, SBG, p. 24.

SILVAFILHO, A. F.; GUIMARÃES, I. P.; VAN SCHMUS, W. R. (2000) Significado geotectônico do magmatismo granítico cálcio-alcalino de alto-K a shoshonítico do Maciço PE-AL, NE Brasil. In: SIMPÓSIO DE GEOLOGIA DO NORDESTE, 18., Recife, 2000. Resumos. Recife, SBG-NO. Boletim n. 16, p 115.

SILVA FILHO, A. F.; GUIMARÃES, I. P.; MARIANO, G.; LUNA, E. A. B. ; SIQUEIRA, D. V. (1998) A evolução magmática do Ciclo Brasiliano no domínio meridional da Província Borborema analisada a partir dos dados de Sm-Nd do Complexo Granítico Proterozóico tarditectônico Santana do Ipanema. In: CONGRESSO BRASILEIRODEGEOLOGIA, 40., Belo Horizonte, 1998. Anais. Belo Horizonte, SBG, p. 12.

SOUZA,L.C.; HUNZIKER, J.; VERKAEREN, J.; LEGRAND, J. M. (1998) A termocronologia $\mathrm{Ar}^{40} / \mathrm{Ar}^{39} \mathrm{e}$ a história termal dos micaxistos encaixantes do maciço granítico de Acari-RN, durante pelo menos $98 \mathrm{Ma}$. In: CONGRESSO BRASILEIRODE GEOLOGIA, 40., Belo Horizonte, 1998. Anais. Belo Horizonte, SBG, p. 14.

WEINBERG, R.; SIAL,A. N.; PESSOA, R. J. R. (2001) Magma flow within Tavares Pluton, northeastern Brazil; compositional and thermal convection. Geological Society of America Bulletin, v. 13, n. 4, p. 508-520. 